\title{
Endophytic Mycobiota of Schinus molle L., (Anacardiaceae) and Peganum harmala L., (Tetradiclidaceae) in Algeria
}

\author{
Khamssa Rouabah (Corresponding Author) \\ Laboratory of Improvement of the Phytosanitary Protection Techniques in Mountainous \\ Agrosystems, Agronomy Department, ISVSA, University Batna1, Batna 05000, Algeria. \\ E-mail: elkhamssa.rouabah@univ-batna.dz
}

\begin{abstract}
Berna Tunali
Department of Plant Protection, Faculty of Agriculture, University Ondokuz Mayis, 55139, Samsun, Turkey. E-mail: btunali@omu.edu.tr
\end{abstract}

\section{Nadia Lombarkia}

Laboratory of Improvement of the Phytosanitary Protection Techniques in Mountainous Agrosystems, Agronomy Department, ISVSA, University Batna1, Batna 05000, Algeria. E-mail: nlombarkia@gmail.com

\section{Oussama Ali Bensaci}

Laboratory of Improvement of the Phytosanitary Protection Techniques in Mountainous Agrosystems, Agronomy Department, ISVSA, University Batna1, Batna 05000, Algeria. E-mail: benssaci.oussama@gmail.com

Received: Jan. 19, 2020

doi:10.5296/jas.v8i1.16530
Accepted: Feb. 1, 2020

Published: Feb. 25, 2020

URL: https://doi.org/10.5296/jas.v8i1.16530

\begin{abstract}
Schinus molle is an arborescent plant that is common in North Africa. It has insecticidal and pharmaceutical activities that are assigned to some active compounds. Harmel is a cosmopolitan species extensively distributed in the world and very common in Algeria especially in the Sahara. This plant is very rich in alkaloids of the $\beta$-carbolines group of
\end{abstract}


which most important are harmine. It has pharmaceutical and agrochemical virtues. Endophytic fungi were isolated from aerial part (leaves and fruits) of Peruvian peppertree $(S$. molle L.) Anacardiaceae and for the first time of the Harmel (Peganum harmala L.) Tetradiclidaceae.Twenty three mycotaxa were identified whose eleven isolated from $S$. molle and twelve isolated from the second plant. The vast majority are included in mitosporic group (Deuteromycota). The frequency of colonization or infection $(\mathrm{FC} \%)$ at leaves of the two plants species is significant comparatively to the fruits.

Keywords: peruvian peppertree, harmel, mycoendophytes, fungi, identification, colonization frequency

\section{Introduction}

Endophytes are microbes that colonize living, internal tissues of plants without causing, any immediate overt negative effects (Stone et al. 2000). As almost all vascular plant species appear to be inhabited by endophytic bacteria or fungi, these represent important components of microbial diversity. The relationship between the host plant and its endophytic shows symbiotic characteristics as the endophytic occupant usually obtains nutrients and protection from the host plant and in return profoundly enhances the fitness of the host by producing certain functional metabolites (Bharathidasan and Panneerselvam 2015).

Schinus molle is an arborescent plant that is common in the tropical regions, more especially in South America and Africa, but spreads as well to the moderated zone of the northern hemisphere. S. molle has insecticidal and pharmaceutical activities (Orozco and Pentz 2005; Ferrero, Chopa et al. 2007). These virtues are essentially assigned to some active components; tannins, triterpenoids, flavonoids, saponins, alkaloids, sterols, terpens, resins and of the essential oils (Cavalher-Machado et al. 2008).

The Harmel; Peganum harmala is a cosmopolitan species extensively distributed in the world and very common in sandy lands, original of the arid, semi-arid zones and the steppes (Lamchouri et al. 2013). This plant is common in North Africa, the middle East, Pakistan, India, Iran, Turkey and has been introduced in America and Australia (Moshiri et al. 2013). In Algeria, this species is common in the high regions of the north, southern Sahara and the mountains of central Sahara.

It is a plant very rich in alkaloids, peganine, isopeganine, dipeganine and the quinazolic derivatives. This species has pharmaceutical and agrochemical virtues and is essentially assigned to the wealth of this plant in alkaloids of the $\beta$-carbolines group of which most important are harmine, harmaline, harmol and harmalol.

It is this context justifies the present survey aiming to identify the mycobiota endophytes from these two plant species, and to see if these two plants, already well known for their medical and agrochemical virtues, can serve like source of endophytic fungi. 


\section{Materials and Methods}

\subsection{Sample Collection}

We opted for the peruvian peppertree and the harmel as two plant species targeted at the rate of their importance in various domains particularly the agrochemical domain, as well as, their chemical compositions.

For the detection and the isolation of endophytic fungi, the aerial parts of the two plants; leaves and fruits were chosen. For the sampling of the foliar part, we chose the most aged and nature leaves because of the importance of limb surface as well as the chemical composition compared to the young leaves. On the other hand, the mature fruits are selected for the sampling. Leaves and fruits were collected from the surroundings of Batna city-Eastern Algeria-(N 3554 18,56, E 00615 05,52) in rainy period (January). The collected leaves and fruits were washed with steril water and carefully stored in polyphene bags and transported to the laboratory for the mycological examination.

\subsection{Sterilization Surface}

The objective of surface sterilization is to eliminate hyphes and spores of epiphytes organisms. We opted thus for the modified protocol of Tejesvi et al. (2006). Sterilized once, leaves of two plants are cut with sterilized blade. The resulting fragments vary in lenght of 2 $\mathrm{mm}$ to $4 \mathrm{~mm}$. These fragments that will be seeded on the culture medium.

\subsection{Culture of Fragments}

The procedure of isolation of endophytic fungi opted for a sowing on the PDA medium (Potato Dextrose Agar) amended to the tetracycline $(100 \mu \mathrm{g} / \mathrm{ml})$, a general antibiotic of action that prevent the bacterial contamination.

The fragments are seeded on Petri dishes containing the PDA. For each of these Petri dishes and for every plant species, we fix 10 fragments. To the total, we have 100 fragments by 10 Petri dishes for every organ/species (200 fragments to the total for each of the two plant species and 400 fragments to the general total). After the sowing, plates were incubated in a dust free cupbroad at the room temperature $\left(25^{\circ} \mathrm{C}\right)$ for 5-7 days. Periodically, cultures are examined in order to observe the development of the emergent fungal colonies of the extremities of the fragments treated.

\subsection{Observation}

The colonies growing from leaves and fruits fragments on PDA plates with different morphology were observed. The fungal cultures were then transferred, subcultured and the pure cultures were maintained on PDA medium. A portion of the growing edge of the colony was picked up with the help of a pair of needles and mounted on a clean slide with lactophenol cotton blue strain. The slide was gently heated in a spirit lamp so as to facilitate the staining and remove air bubbles. If any, the excess stain was removed with the help of tissue paper and then the cover slip was sealed with transparent nail polish. The slide was observed under a compound microscope. 


\section{Ml Macrothink}

\subsection{Frequency of Colonization (FC\%)}

The frequency of colonization or infection (FC\%) is calculated while being based on the method of Fisher and Petrini (1987) In Tejesvi et al. (2006), given like follows:

$$
F C \%=N c / N t \times 100
$$

Where: $\mathbf{F C}=$ Frequency of colonization or infection.

$\mathbf{N}_{\mathbf{c}}=$ The number of segments colonized by a species or a fungal group.

$\mathbf{N}_{\mathbf{t}}=$ The total number of the segments.

\subsection{Identification of Fungi}

The isolates were grouped into sporulating and non sporulating forms. Sporulating structures were considered as diagnostic characters in the identification of fungi. Using standard taxonomic (Ellis 1971; Ellis 1976; Barnett and Hunter 1998), the isolates were identified and assigned to respective genera and species. In the absence of sporulation, the taxonomic identity of several non sporulating forms recovered is not known and they are recognized merely based on cultural characters such as colony morphology, growth rate and pigmentation (sterile mycelium).

\section{Results}

\subsection{Frequency of Colonization or Infection (FC\%)}

The frequency of colonization or infection (FC\%) for the selected fragments is represented in the table 1 .

Table 1. Frequency of colonization (FC\%) at S. molle and P. harmala

\begin{tabular}{c|c|c}
\hline Species & S. molle & P. harmala \\
\hline Leaves & $95 \%$ & $98 \%$ \\
\hline Fruits & $88 \%$ & $56 \%$ \\
\hline
\end{tabular}

\subsection{Specific Composition of Fungal Isolates Detected at S. Molle and P. Harmala}

We have twenty three (23) fungi isolates of which eleven (11) mycotaxons is identified from

the $S$. molle and twelve (12) fungi are isolated from the second plant species (table 2 and figures 1,2). 
Table 2. Composition of mycoendophytes detected at S. molle and P. harmala

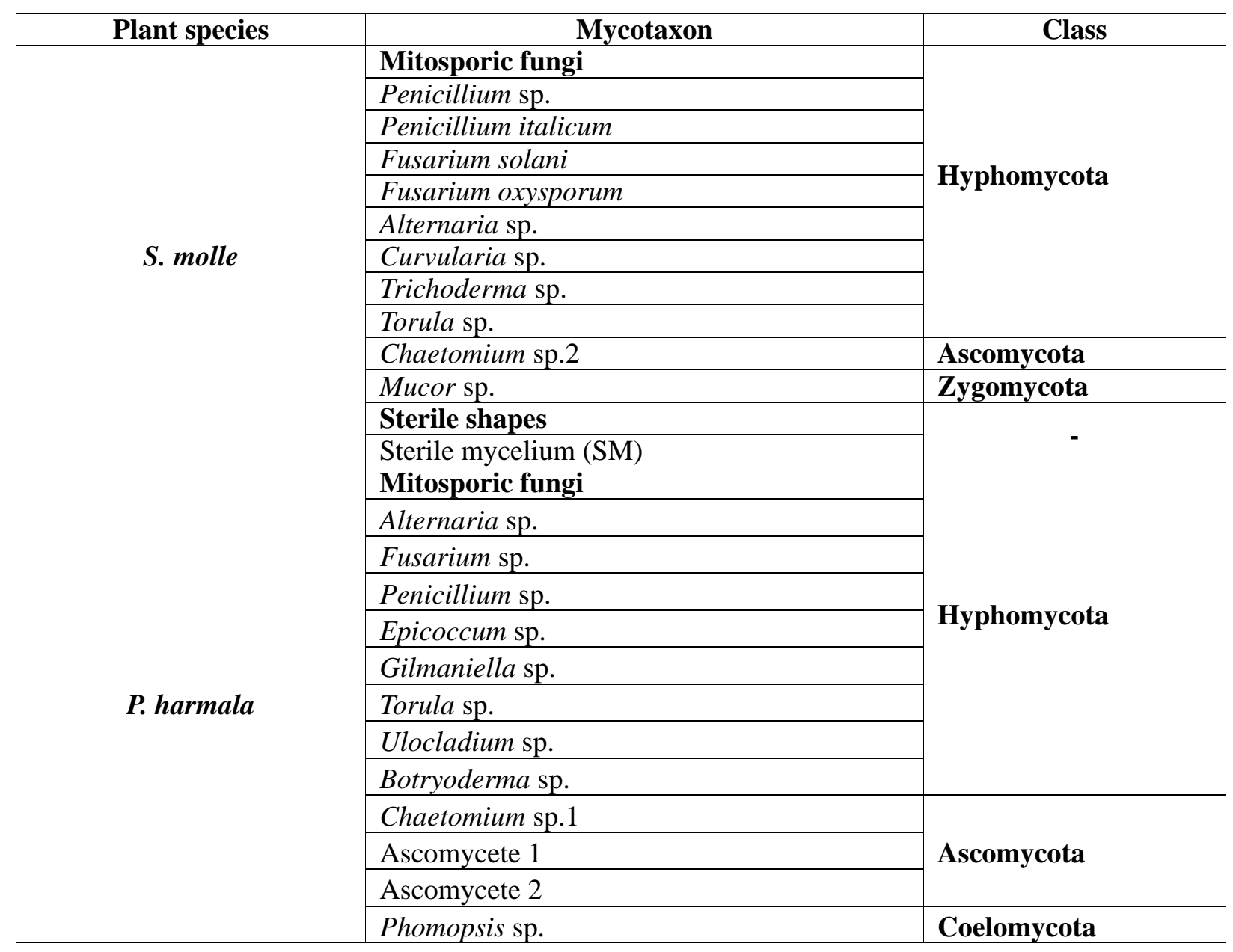

According to results, the qualitative status of mycobiota endophytes detected on plant species, we reveal that the number of isolated mycoendophytes is relatively insignificant.

For the first plant species ( $S$. molle), the group of mitosporic fungi and specifically the class of Hyphomycota contains the most dominant genus (Penicillium, Fusarium, Alternaria, Curvularia, Trichoderma and Torula) comes first, then the class of Ascomycota and Zygomycota with only one genus for each; Chaetomium and Mucor respectively.

On the other hand, P. harmala contains eight (8) genus in the class of Hyphomycota (Alternaria, Fusarium, Penicillium, Epicoccum, Gilmaniella, Torula, Ulocladium and Botryoderma). The class of Ascomycota is composed of three (3) genus with only one genus (Phomopsis) for the class of Coelomycota. 


\section{Macrothink}
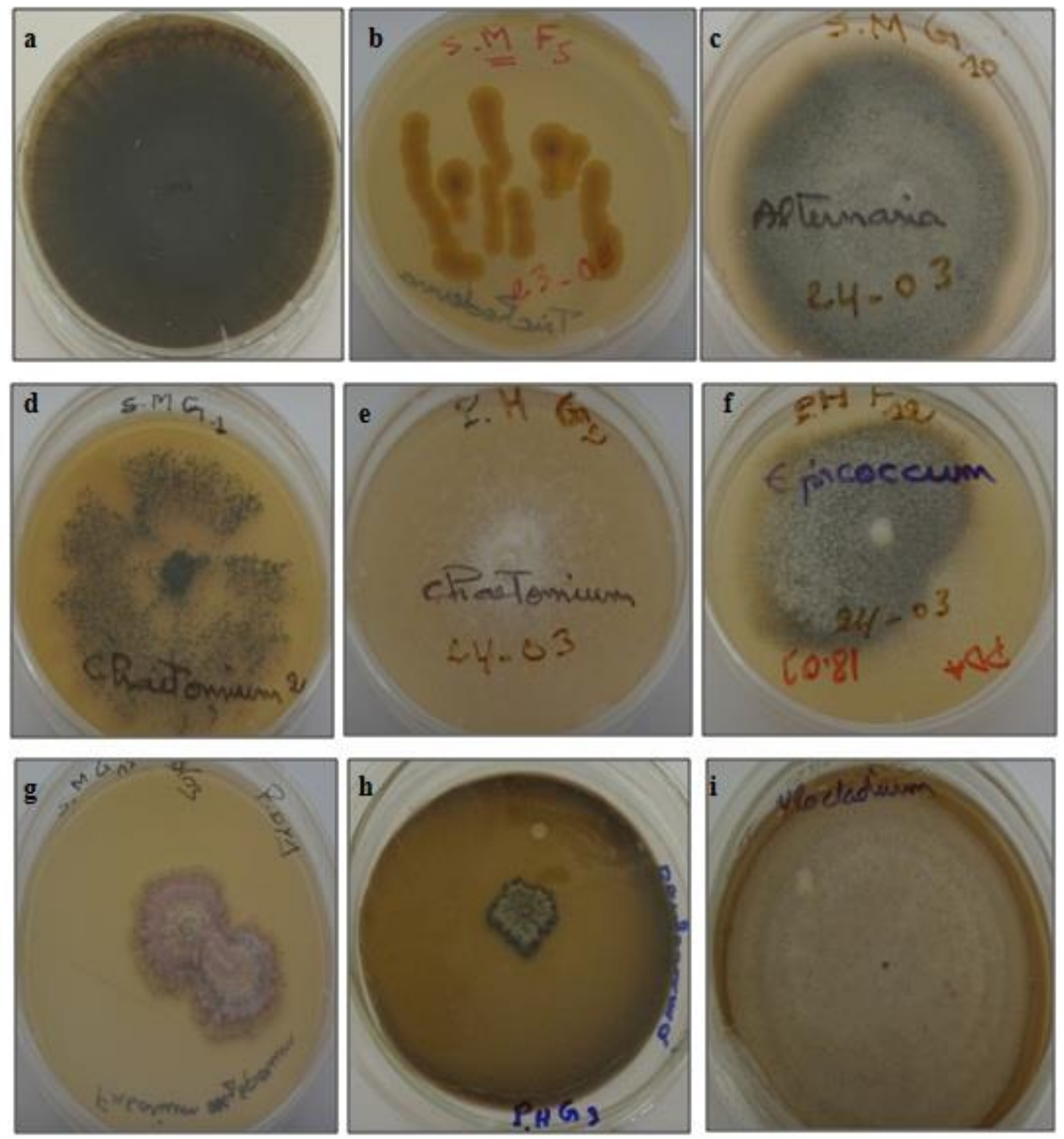

Figure 1. Examples of pure cultures of the endophytic fungi isolated from $S$. molle and $P$. harmala; (a): Curvularia sp., (b): Trichoderma sp., (c): Alternaria sp., (d), (e): Chaetomium sp., (f): Epicoccum sp., (g): Fusarium oxysporum, (h): Botryoderma sp., (i): Ulocladium sp 


\section{Macrothink}
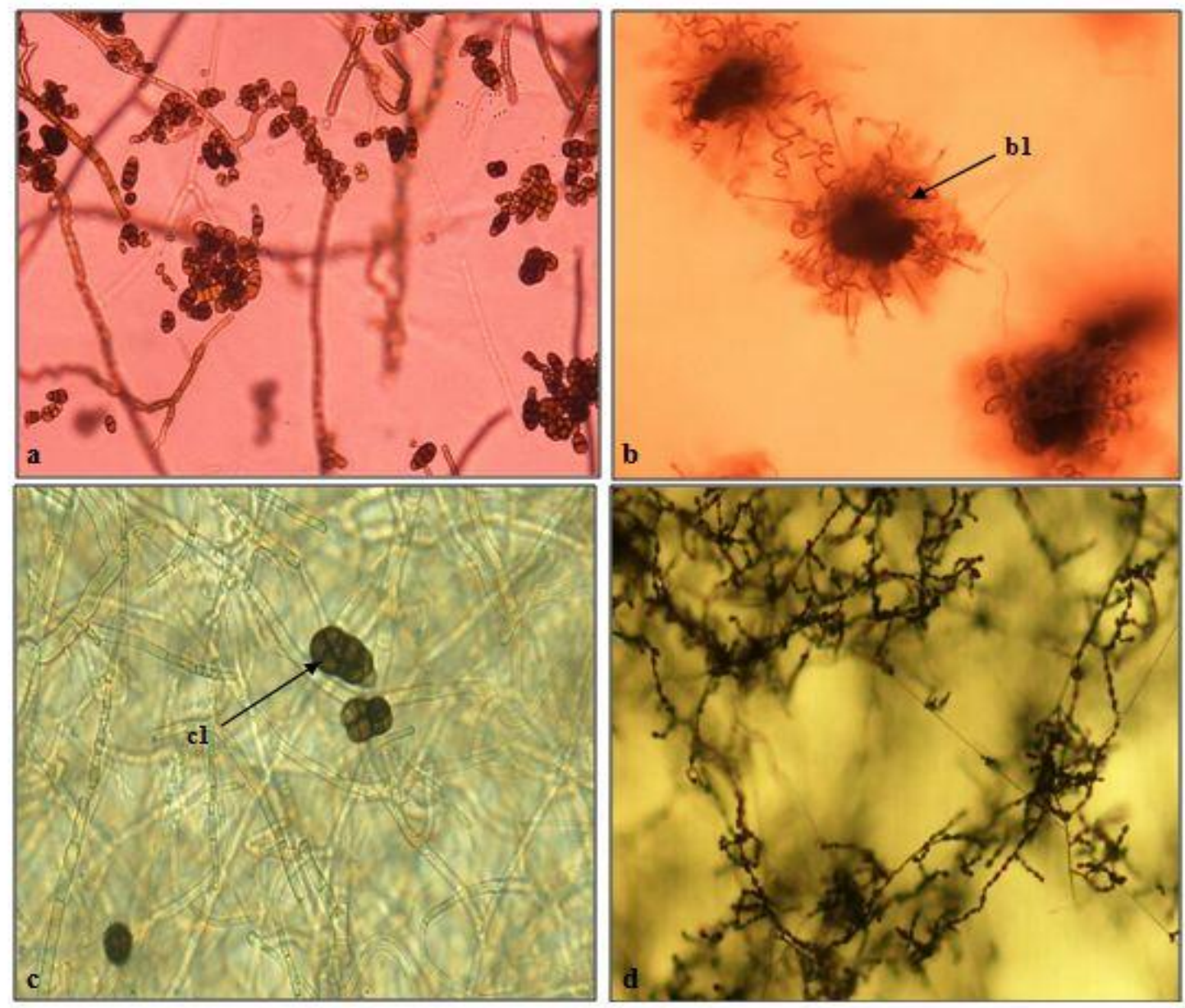

Figure 2. Microscopic illustrations of some mycotaxons; (a): Curvularia sp. (G×100), (b):

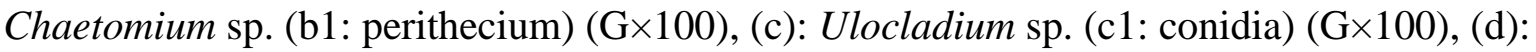
Alternaria sp. $(\mathrm{G} \times 40)$

\section{Discussion}

Our work demonstrates the presence of endophytic fungi associated to leaves and fruits of the two studied plant species; peruvian peppertree ( $S$. molle) and for the first time at the harmel ( $P$. harmala). Endophytic fungi are one of the groups of microorganisms that are very diverse and unexplored. These make symbiotic associations and can produce beneficial substances for the host (Khan et al. 2007).

We noted that the colonization of leaves and fruits by mycoendophytes is significant on the quantitative statute, indeed, the ubiquity of endophytes is an aspect shared between various studied phytotaxons. This aspect can be bound to an anatomical, biochemical, and physiological predispositions of studied aerial parts, opposite to the infections and colonizations of endophytes. Thus, the ubiquity of endophytes in nature is always selective, this selective colonization can lead to the production of bioactives substances in the host plant (Huang et al. 2008). 
The rate of infection of the aerial parts; leaves and fruits, generally evolves with the age of these last. Kumaresan and Suryanarayanan (2002) demonstrated that the rate of infection of Rhizophora apiculata (Rhizophoraceae) increases for the mature fruits and adult leaves. Goveas et al. (2011) demonstrated that the frequency of colonization of the medecinal plant Coscinium fenestratum (Menispermaceae) by endophytes increases with the age of leaves; $3,33 \%$ for the young leaves, $21,02 \%$ for the mature leaves and $53,33 \%$ for the adult leaves.

This colonization raised of the aged leaves is with time due to a superinfection of leaves by the inoculum carried with air (Suryanarayanan and Thennarasan 2004).

The same observations have been expressed for conifers, Plumeria rubra, Trachycarpus fortunei, Azadirachta indica (Suryanarayanan and Thennarasan 2004), the Gramineous (Bacon and White 1994), the Palmaceses (Rodrigues 1994), the Gymnospermeses and at some tropical plants (Kumaresan and Suryanarayanan 2002).

On the other hand, no information is available, concerning the mechanisms reacting the modes of the natural infection as well as the internalisation of fungi, within tissues of the two studied plant species; $S$. molle and P. harmala.

The number of isolated fungi is relatively insignificant with the predominance of the hyphomycetes fungi, in particular, Fusarium, Torula and Alternaria. This very low number can be explained by the presence of chemical factors illustrated by specific compounds within the host plant as the sesquiterpens, flavonoids, tannins as well as the resins (Goveas et al. 2011).

According to Clay (1993) the host plant can be at the origin of some secondary metabolites that cannot only inhibit the growth of endophytes on their tissues, but also to limit their propagation and even to restrict the number of associated fungi. This observation can be projected on our results to explain the fact that some endophytes, as Fusarium and Chaetomium, are especially frequent, notably on the fruits of $S$. molle and the leaves of the second plant; P. harmala.

The majority of endophytes detected are arranged within the mitosporic group (Deuteromycete). Practically, a multitude of conducted research on the subject, attest that the Deuteromycetes that represent the sexual formes, predominate regardless of the taxonomic nature of the host plant (Marquez et al. 2007; Huang et al. 2008; Costa et al. 2012; Singh 2013).

In contrast with our work, the survey of Rodrigues and Samuels (1999) range on a medicinal plant Anacardiaceae; Spondias mombin, proved that the dominance endophyte is for the Ascomycete; Phomopsis sp.

The mitosporic fungi specifically the class of the Hyphomycota has been considered as the most predominant group in the majority of the plants colonized by the mycoendophytes, it is justified by a lot of studies (Seena and Sridhar 2004; Khan et al. 2007; Mangunwardoyo et al. 2012; Jena and Tayung 2013; Han et al. 2013; Sharma and Kumar 2013; Shi et al. 2013; Suciatmih and Rahmansyah 2013; D'souza and Bhat 2013). The nature of dominance of the 


\section{Al Macrothink}

Journal of Agricultural Studies

ISSN 2166-0379

2020, Vol. 8, No. 1

Hyphomycetes can be assigned to their capacity to colonize their host quickly while producing abundant asexual spores (Jena and Tayung 2013).

This class predominates the species Azadirachta indica (Meliaceae) with a rate of colonization of $61 \%$, followed by the Ascomycota $(21 \%)$ and the sterile mycelium (18\%). The genus Fusarium, Trichoderma and Chaetomium being the most frequently isolated (Tejesvi et al. 2006). The same results have been expressed for the two medicinal plants; Solanum rubrum and Morinda pubescence where the fungal composition for the first species is of $65 \%$ Hyphomycota, $10 \%$ Coelomycota and $10 \%$ sterile mycelium, while the rate of colonization is of $86 \%$ Hyphomycota, $8 \%$ Ascomycota, $4 \%$ Coelomycota and $16 \%$ sterile mycelium for the second medicinal plant (Jena and Tayung 2013).

The genus of Trichoderma and Fusarium are isolated in this study as endophytes. Whereas these two fungi are fundamentally pathogenic fungi, but sometimes, they are modified by mutation and become no-pathogenic endophytes (Nagaraja 2011). However, in the last years, Trichoderma sp. has also been returned like endophytic fungi (Chaverri et al. 2011).

\section{References}

Bacon, C. W., \& White, J. F. (1994). Biotechnology of endophytic fungi. Jr. CRC Press, Boca Baton, Florida. p. 214.

Barnett, H. L., \& Hunter, B. B. (1998). Illustrated genera of imperfect fungi. (4 ${ }^{\text {th }}$ ed.). USA: St. Paul, Minnesota. p.218.

Bharathidasan, R., \& Panneerselvam, A. (2015). Isolation of fungi from Suaeda monoica, Karankadu Mangrove forest of Ramanathapuram Dt. International Journal of Advanced Research in Biological Sciences, 2(9), 163-166.

Cavalher-Machado, S. C., Rosas, E. C., Brito, F. A., Heringe, A. P., Oliveira, R. R., Kaplan, M. A. C., \& Henriques, M. D. G. M. O. (2008). The anti-allergic activity of the acetate fraction of Schinus terebinthifolius leaves in $\operatorname{IgE}$ induced mice paws edema and pleurisy. $\begin{array}{llll}\text { International Immunopharmacology, } & 8, & 1552-1560 .\end{array}$ https://doi.org/10.1016/j.intimp.2008.06.012

Chaverri, P., Gazis, R., \& Samuels, G. (2011). Trichoderma amazonicum, a new endophytic species on Hevea brasiliensis and H. guianensis from the Amazon basin. Mycologia, 103(1), 139-151. https://doi.org/10.3852/10-078

Clay, K. (1993). The ecology and evolution of endophytes. Agriculture, Ecosystems and Environment, 44, 39-64. https://doi.org/10.1016/0167-8809(93)90038-Q

Costa, I. P. M. W., Maia, L. C., \& Cavalcanti, M. A. (2012). Diversity of leaf endophytic fungi in mangrove plants of northeast Brazil. Brazilian Journal of Microbiology, 1165-1173. https://doi.org/10.1590/S1517-83822012000300044

D'souza, M. A., \& Bhat, D. J. (2013). Occurrence of microfungi as litter colonizers and endophytes in varied plant species from the Western Ghats forests, Goa, India. Mycosphere, 4(3), 567-582. https://doi.org/10.5943/mycosphere/4/3/10 


\section{Macrothink}

Journal of Agricultural Studies

ISSN 2166-0379

2020, Vol. 8, No. 1

Ellis, M. B. (1971). Dematiateous hyphomycetes. Commonwealth mycological institute Kew, Surrey, England. p. 608.

Ellis, M. B. (1976). More dematiateous hyphomycetes. Commonwealth mycological institute Kew, Surrey, England.

Ferrero, A. A., Chopa, C. S., Gongalez, J. O. W., \& Alzogaray, R. A. (2007). Repellence and toxicity of Schinus molle extracts on Blattella germanica. Fitoterapia, 78, 311-314. https://doi.org/10.1016/j.fitote.2006.11.021

Goveas, S. W., Madtha, R., Nivas, S. K., \& D'souza, L. (2011). Isolation of endophytic fungi from Coscinium fenestratum -a red listed endangered medicinal plant. Eurasia J. Biosci., 5, 48-53. https://doi.org/10.5053/ejobios.2011.5.0.6

Han, L. R., Wang, Z. H., Zhang, H. J., Xue, L. S., Feng, J. T., \& Zhang, X. (2013). Isolation of endophytic fungi from Tripterygium wilfordii and their insecticidal activities. African Journal of Microbiology Research, 7(9), 771-776.

Huang, W. Y., Cai, Y. Z., Hyde, K. D., Corke, H., \& Sun, M. (2008). Biodiversity of endophytic fungi associated with 29 traditional chinese medicinal plants. Fungal Diversity, $33,61-75$.

Jena, S. K., \& Tayung, K. (2013). Endophytic fungal communities associated with two ethno-medicinal plants of similipal biosphere reserve, India and their antimicrobial prospective. Journal of Applied Pharmaceutical Science, 3(4), 7-12.

Khan, R., Shahzad, S., Choudhary, M. I., Khan, S. A., \& Ahmad, A. (2007). Biodiversity of the endophytic fungi isolated from Calotropis procera (AIT.) R. BR. Pak. J. Bot., 39(6), 2233-2239.

Kumaresan, V., \& Suryanarayanan, T. S. (2002). Occurrence and distribution of endophytic fungi in a mangrove community. Mycological Research, 105, 1388-1391. https://doi.org/10.1017/S0953756201004841

Lamchouri, F., Zemzami, M., Jossang, A., Settaf, A., Israili, Z. H., \& Lyoussi, B. (2013). Cytotoxicity of alkaloids isolated from Peganum harmala seeds. Pak. J. Pharm. Sci., 26(4), 699-706.

Mangunwardoyo, W., Suciatmih, \& Gandjar, I. (2012). Frequency of endophytic fungi isolated from Dendrobium crumenatum (Pigeon orchid) and antimicrobial activity. Biodiversitas. 13(1), 34-39. https://doi.org/10.13057/biodiv/d130107

Marquez, S. S. Bills, G. F., \& Zabalgogeazcoa, I. (2007). The endophytic mycobiota of the grass Dactylis glomerata. Fungal Diversity, 27, 171-195.

Moshiri, M., Etemad, L., Javidi, S., \& Alizadeh, A. (2013). Peganum harmala intoxication, a case report. Avicenna Journal of Phytomedicine, 3(3), 288-292.

Nagaraja, T. G. (2011). Isolation and identification of seasonal endomycophytes of inner bark of Castanospermum australe a. cunn and c. The Bioscan, 6(2), 263-265. 
Orozco, O. L., \& Lentz, D. L. (2005). Poisonous plants and their uses as insecticides in Cajamarca, Peru. Bconomic Botany, 59(2), 166-173. https://doi.org/10.1663/0013-0001(2005)059[0166:PPATUA]2.0.CO;2

Rodrigues, K. F. (1994). The foliar endophytes of the Amazonian palm Euterpe oleracea. Mycologia, 86, 376-385. https://doi.org/10.1080/00275514.1994.12026423

Rodrigues, K. F., \& Samuels, G. J. (1999). Fungal endophyte of Spondias mombin leaves in

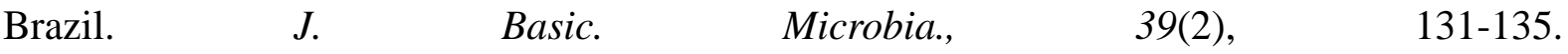
https://doi.org/10.1002/(SICI)1521-4028(199905)39:2<131::AID-JOBM131>3.0.CO;2-9

Seena, S., \& Sridhar, K. R. (2004). Endophytic fungal diversity of 2 sand dune wild legumes from the southwest coast of India. Canadian Journal of Microbiology, 50, 1015-1021. https://doi.org/10.1139/w04-094

Sharma, R., \& Kumar, B. S. V. (2013). Isolation characterization and antioxidant potential of endophytic fungi of Ocimum sanctum Linn. (Lamiaceae). Indian Journal of Applied Research. 3(7), 5-10. https://doi.org/10.15373/2249555X/JULY2013/23

Shi, Y., Zhang, X., \& Lou, K. (2013). Isolation, characterization, and insecticidal activity of an endophyte of drunken horse grass, Achnatherum inebrians. Journal of Insect Science. 13(5), 1-12. https://doi.org/10.1673/031.013.15101

Singh, S. K. (2013). Endophytic fungi from Jatropha curcus: A preliminary study. Journal of Pharmaceutical and Scientific Innovation, 26-29. https://doi.org/10.7897/2277-4572.02209

Stone, J. K., Bacon, C. W., \& White, J. F. (2000). An overview of endophytic microbes: endophytism defined. In C.W. Bacon, \& J.F. White (Eds), Microbial endophytes (pp. 3-30). New York.

Suciatmih, \& Rahmansyah, M. (2013). Endophytic fungi isolated from mangrove plant and have antagonism role against fusarium wilt. ARPN Journal of Agricultural and Biological Science. 8(3), 251-257.

Suryanarayanan, T. S., \& Thennarasan, S. (2004). Temporal variation in endophyte assemblages of Plumeria rubra leaves. Fungal Diversity, 15,197-204.

Tejesvi, M. V., Mahesh, B., Nalini, M. S., Prakash, H. S., Kini, K. R., Subbiah, V., \& Shetty, H. S. (2006). Fungal endophyte assemblages from ethnopharmaceutically important medicinal trees. Can. J. Microbiol., 52, 427-435. https://doi.org/10.1139/w05-143

\section{Copyright Disclaimer}

Copyright for this article is retained by the author(s), with first publication rights granted to the journal.

This is an open-access article distributed under the terms and conditions of the Creative Commons Attribution license (http://creativecommons.org/licenses/by/4.0/). 